\title{
Influence of the water level in the work area on the hydrate formation process
}

\author{
Anton V. Meleshkin ${ }^{1, *}$, and Dmitriy S. Elistratov ${ }^{2}$ \\ ${ }^{1}$ Novosibirsk State University, 630090 Novosibirsk, Russia
}

\begin{abstract}
This article describes a fundamentally new method for obtaining gas hydrates, based on self-organization in a closed working section of the cyclic boiling-condensation process of the gas-hydrate generator. A special feature of this method is the high rate of hydrate formation at low energy costs and, as a consequence, the expected efficiency of new technologies built on its basis over analogues. A series of experiments was performed, which shows the effect of the water level on the work site on the hydrate formation process.
\end{abstract}

\section{Introduction}

As early as the beginning of the 20th century, technological proposals for the storage and transportation of natural gas in the hydrated state appeared. This method draws the attention of experts for a long time because of the property of gas hydrates to concentrate large volumes of gas at relatively low pressures. Without a pipeline, a promising way of transporting gas is to convert it into a gas hydrate (solid) state and transport it at atmospheric pressure and low temperature $\left(\begin{array}{llll}-10 & \ldots & -20 & { }^{\circ} \mathrm{C}\end{array}\right)$ [1]. The properties of gas hydrates, the main conditions and the features of their formation are described in [2-4] and some other works; the types of their crystallization, the mechanisms of formation and decomposition of gas hydrates are presented [5-11].

A method for producing gas hydrates based on shock-wave action on gas-liquid media was proposed, the intensification of the hydrate formation process is caused by the imposition of several factors such as an increase in the contact surface of hydrate-forming gas water due to the destruction of the bubbles by the shock wave, the transfer of the system far into the region of formation hydrates and the acceleration of bubbles with respect to water [12-13]. We continue to look for effective ways to intensify the formation of hydrates with the help of mechanical and thermal effects on gas-liquid media [14-17].

\section{Experimental setup}

The working site, which is a sealed vessel with a height of $740 \mathrm{~mm}$ and a section of $150 X 150 \mathrm{~mm}$ (Fig.1). Two walls of the vessel are made of an optically transparent material and allow observing the processes taking place inside the working area. Maintenance of the

\footnotetext{
* Corresponding author: mav@itp.nsc.ru
} 
required temperature inside the installation is carried out using the built-in cooling system (water jacket). The lower cover of the installation does not have thermal insulation and is heated from the external environment. The temperature was measured by the DTS204PT100 sensor, and the pressure measurement by the PD-100 sensor. The installation allows to carry out research in a wide range of temperatures (from -10 to $60^{\circ} \mathrm{C}$ ) and pressure (from 0.1 to $10 \mathrm{MPa}$ ).

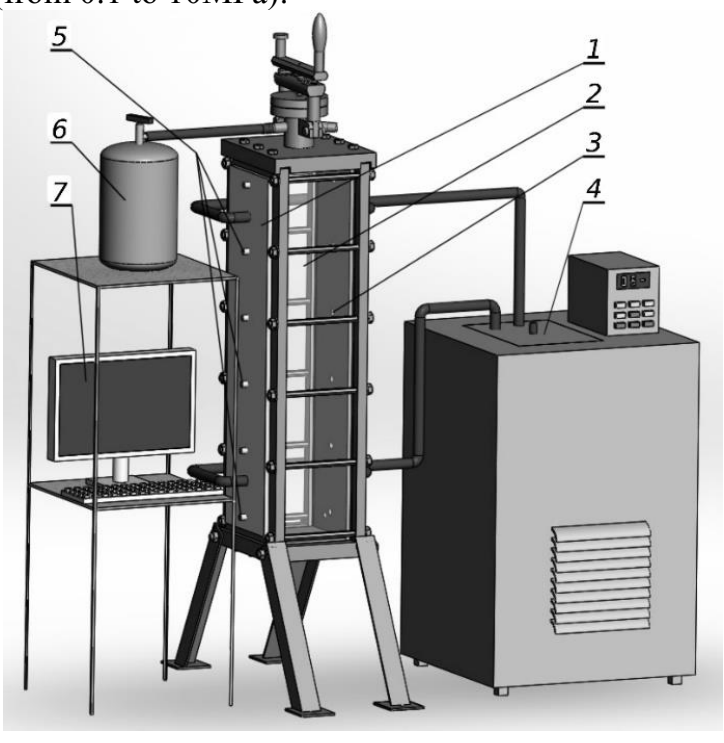

Fig. 1. The schematics of the unit: 1 - Side walls; $2-$ Working area; 3 - temperature sensor; 4 - cryostat; 5 pressure sensors; 6 - gas tank; 7 - PC.

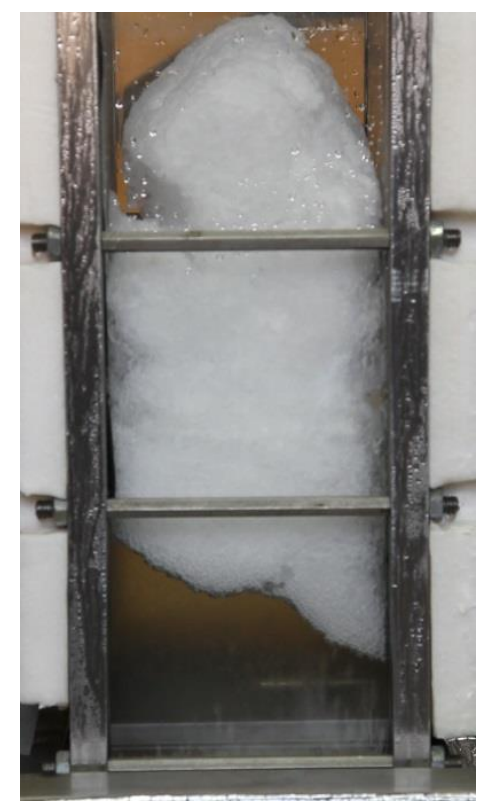

Fig. 2. Gas-hydrate gained in the experiment.

\section{Method and result}

The essence of the experiment was as follows. The reaction vessel was filled with water, the volume of which varied from 1.5 to 6 liters. The water was cooled to a temperature of 7 ${ }^{\circ} \mathrm{C}$, then a gaseous freon R-134A, weighing $0.3 \mathrm{~kg}$, was fed into the chamber. Since the walls of the vessel had a negative temperature, Freon quickly liquefied and sank to the bottom. After the gas supply to the working area had ceased, the pressure equalized and the boiling began on the lower lid of the vessel. Due to intense boiling, a large number of bubbles of freon vapor formed. Rising to the surface of the vapor in the bubbles was cooled and conditions were created for the formation of Freon Hydrate. On the walls of the bubbles began to build up a hydrate film. Having reached the free surface of the liquid, the bubbles collapsed, leaving behind them hydrated flakes. Pairs of freon, not converted to hydrate, condense on cooled walls and descended to the bottom of the vessel where they were again included in the boiling process. From the description it can be seen that the process is cyclical and continues until all the liquid Freon, boiling off, goes to the hydrate (Fig. 2). The intensity of the process depends on both the removal of heat from the side walls and the supply of heat to the lower part of the installation, and from the distance traveled by the bubbles during boiling for each cycle. On fig. 3 shows the graphs of the growth of the gas hydrate "hat" from the distance traveled by a bubble from the bottom of the installation to the surface of the water. 


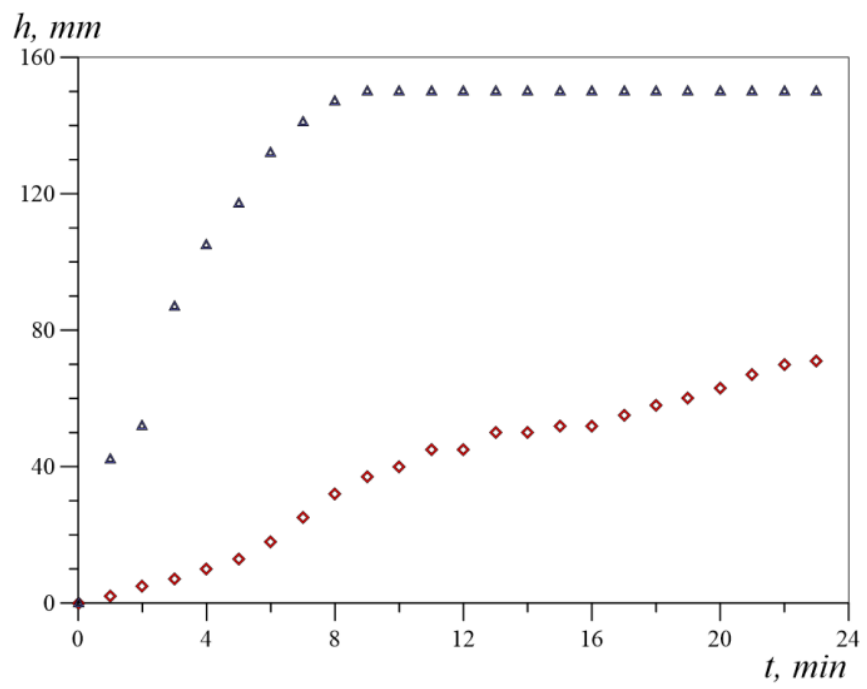

Fig. 3. Chart of growth of hydrate mass R-134A in the vessel depending on the level of water: Triangles - Height of water column is $50 \mathrm{~mm}$, Circle - Height of water column is $230 \mathrm{~mm}$.

\section{Conclusion}

A new method for obtaining gas hydrates is developed, based on self-organization of the cyclic boiling-condensation process of the gas-hydrate-forming agent in a closed water volume. This method is characterized by good energy efficiency. The influence of the height of the water column on the formation of hydrates is shown.

This work was supported by the Russian Science Foundation, project No. 18-19-00124.

\section{References}

1. J. Gudmundsson, M. Mork, O. Graff, Proc. 4th Intern. Conf. gas hydrates (2002)

2. Y. F. Makogon, Hydrates of Hydrocarbons (PennWell Books, Texas, 1997)

3. V. S. Yakushev, V. A. Istomin, Physics and Chemistry of Ice, 136 (1993)

4. E. D. Sloan, C. A. Koh, Clathrate hydrates of natural gases (CRC Press, Boca Raton, 2008)

5. V. Sh. Shagapov, N. G. Musakaev, M. K. Khasanov, Int. J. Heat Mass Transfer 84, 1030 (2015)

6. V. Sh. Shagapov, M. K. Khasanov, N. G. Musakaev, Ngoc Hai Duong, Int. J. Heat Mass Transfer 107, 347 (2017)

7. N. G. Musakaev, M. K. Khasanov, S. L. Borodin, Int. J. Heat Mass Transfer 118, 455 (2018)

8. M. Z. Faizullin, A. V. Vinogradov, V. P. Koverda, Chem. Eng. Sci. 130, 135 (2015)

9. S. Y. Misyura, Sci. Rep. 6, 30324 (2016)

10. V. E. Nakoryakov, S. Y. Misura, S. L. Elistratov, A. Yu. Manakov, A. A. Sizikov, J. Eng. Thermophys. 22, 169 (2013)

11. V. E. Nakoryakov, S. Y. Misura, J. Eng. Thermophys. 25, 24 (2016) 
12. V.E. Dontsov, A.A. Chernov, Int. J. Heat Mass Transfer 52, 4919 (2009)

13. A.A. Chernov, V.E. Dontsov, Int. J. Heat Mass Transfer 54, 4307 (2011)

14. A.A. Chernov, A.A. Pil'nik, D.S. Elistratov, I.V. Mezentsev, A.V. Meleshkin, M.V. Bartashevich, M.G. Vlasenko, Sci. Rep. 7, 40809 (2017)

15. A.A. Chernov, D.S. Elistratov, I.V. Mezentsev, A.V. Meleshkin, A.A. Pil'nik, Int. J. Heat Mass Transfer 108, 1320 (2017)

16. V.E. Nakoryakov, A.N. Tsoi, I.V. Mezentsev, A.V. Meleshkin, J. Eng. Thermophys. 23 (2014)

17. V.E. Nakoryakov, A.N. Tsoi, I.V. Mezentsev, A.V. Meleshkin, T and A. 21, 279 (2014) 